\title{
The Grignard Reaction - Unraveling a Chemical Puzzle
}

\author{
Raphael Mathias Peltzer, Jürgen Gauss, Odile Eisenstein,** and Michele Cascella*
}

Cite This: J. Am. Chem. Soc. 2020, 142, 2984-2994

Read Online

ABSTRACT: More than 100 years since its discovery, the mechanism of the Grignard reaction remains unresolved. Ambiguities arise from the concomitant presence of multiple organomagnesium species and the competing mechanisms involving either nucleophilic addition or the formation of radical intermediates. To shed light on this topic, quantum-chemical calculations and $\mathrm{ab}$ initio molecular dynamics simulations are used to study the reaction of $\mathrm{CH}_{3} \mathrm{MgCl}$ in tetrahydrofuran with acetaldehyde and fluorenone as prototypical reagents. All organomagnesium species coexisting in solution due to the Schlenk equilibrium are found to be competent reagents for the nucleophilic pathway. The range of activation energies displayed by all of these compounds is relatively small. The most reactive species are a

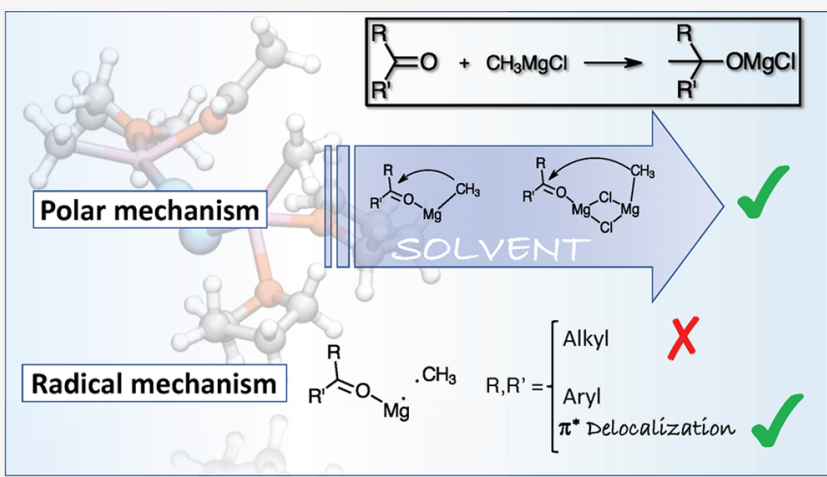
dinuclear $\mathrm{Mg}$ complex in which the substrate and the nucleophile initially bind to different $\mathrm{Mg}$ centers and the mononuclear dimethyl magnesium. The radical reaction, which requires the homolytic cleavage of the $\mathrm{Mg}-\mathrm{CH}_{3}$ bond, cannot occur unless a substrate with a low-lying $\pi^{*}(\mathrm{CO})$ orbital coordinates the $\mathrm{Mg}$ center. This rationalizes why a radical mechanism is detected only in the presence of substrates with a low reduction potential. This feature, in turn, does not necessarily favor the nucleophilic addition, as shown for the reaction with fluorenone. The solvent needs to be considered as a reactant for both the nucleophilic and the radical reactions, and its dynamics is essential for representing the energy profile. The similar reactivity of several species in fast equilibrium implies that the reaction does not occur via a single process but by an ensemble of parallel reactions.

\section{INTRODUCTION}

The Grignard reaction is a prominent textbook process to form carbon-carbon bonds. ${ }^{1}$ In this reaction, the so-called Grignard reagent, an organomagnesium species $\mathrm{RMgX}$ where $\mathrm{R}$ is an organic residue and $\mathrm{X}$ is a halogen (usually $\mathrm{Cl}$ or $\mathrm{Br}$ ), promotes the addition of its organic residue to an electrophilic substrate. Discovered by Victor Grignard ${ }^{2}$ already in 1900, Grignard reagents rapidly became important compounds for organic synthesis in research laboratories and in industry. ${ }^{3}$ Even though the reaction today is applied to a large variety of electrophiles, the prototypic substrates are carbonyl moieties $\mathrm{R}^{1} \mathrm{R}^{2}(\mathrm{C}=\mathrm{O})$ yielding a magnesium-alcoholate (eq 1$)$. The $\mathrm{R}^{1}$ and $\mathrm{R}^{2}$ residues usually include hydrogen as well as alkyl-, vinyl-, or aryl- groups. The Grignard reaction usually takes place in ethereal solvents, the final alcohol product being obtained by hydrolysis.

$$
\mathrm{RMgX}+\mathrm{R}^{1} \mathrm{C}(\mathrm{O}) \mathrm{R}^{2} \rightarrow \mathrm{R}^{1} \mathrm{C}(\mathrm{OMgX})(\mathrm{R}) \mathrm{R}^{2}
$$

Despite more than 100 years of extensive studies, the mechanism of this reaction has remained elusive, with little quantitative information and missing consensus. Difficulties in elucidating this mechanism are prominently related to the fact that the ethereal solutions of Grignard reagents contain a variety of chemical species. ${ }^{4,5}$ In fact, the nominal reactant $\mathrm{RMgX}$ is just a condensed representation of numerous mono- and polymetallic molecules that coexist at equilibrium (eq 2) and whose relative abundance depends on the nature of $\mathrm{R}$ and $\mathrm{X}$ as well as the experimental conditions. ${ }^{4,6}$

$$
2 \mathrm{RMgCl} \leftrightharpoons \mathrm{MgR}_{2}+\mathrm{MgCl}_{2}
$$

Furthermore, while the polarity of the $\mathrm{C}^{(\delta-)}-\mathrm{Mg}^{(\delta+)}$ bond suggests that the Grignard reagent acts as a nucleophile, it has been argued that an electron-transfer mechanism may occur in the presence of appropriate substrates. ${ }^{5}$

This multifaceted aspect of the Grignard chemistry is per se fascinating; in fact, the lack of understanding of its molecular mechanisms has slowed progress in the rational design of more efficient variants of the reaction. Indeed, while the efficiency of Grignard reagents has been heuristically improved, for example by the synergistic effect of additives like alkali ions, the reasons for these improvements remain unclear. ${ }^{7}$ Elucidation of the mechanism of the basic Grignard reaction is the required step to better understand a wide variety of related reactions.

Received: November 2, 2019

Published: January 17, 2020 
Although the nucleophilic mechanism (also known as the polar mechanism) is currently recognized in the literature as a route to the alcohol product, no experimental study was able to assign the relative reactivity of the various forms of the organomagnesium species. In parallel, experimental evidence consistently supported the presence of an alternative mechanism (called radical or single electron-transfer mechanism) involving the formation of radical intermediates (Figure 1). In particular, products were detected, which could not
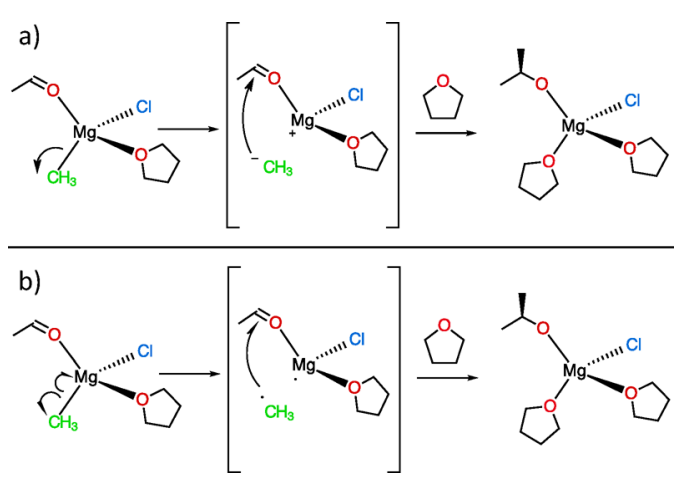

Figure 1. Schematic representation of possible mechanisms for the Grignard reaction: (a) polar mechanism, heterolytic $\mathrm{Mg}-\mathrm{C}$ bond breaking, with subsequent formation of a nucleophilic carbon that adds to the electrophilic carbonyl carbon; or (b) radical mechanism, homolytic $\mathrm{Mg}-\mathrm{C}$ bond breaking, with subsequent recombination of the species with unpaired electrons.

originate from a nucleophilic addition but could be only obtained through a combination of organic radicals. ${ }^{8-15}$ Furthermore, electron spin resonance spectroscopy identified the presence of ketyl radicals in benzophenone/Grignard reagent mixtures. ${ }^{16}$ Factors favoring the radical mechanism were searched. Thus, using the distribution of products as an indicator for the mechanism, Ashby and co-workers inferred that an electron-transfer mechanism depends on the reduction potential of the substrate, the oxidation potential of the Grignard reagent, and the polarity of the solvent. Ketones with low reduction potential favored the radical mechanism. Indeed, a radical-type reaction was established for aromatic and conjugated ketones (such as benzophenone and fluorenenone) in the case of tertiary as well as primary Grignard reagents. ${ }^{14}$

Chiral Grignard reagents were also used to probe the reaction pathway. It was in this way shown that chiral secondary Grignard reagents react largely, but not exclusively, by a radical mechanism with benzophenone, but essentially by nucleophilic addition with benzaldehyde. ${ }^{17,18}$ The secondary $\mathrm{H} / \mathrm{D}$ kinetic isotope effect indicated that the competition between the nucleophilic and the single electron-transfer mechanisms depends on the reagent (i.e., magnesium or lithium organometallic species) and the substrate. ${ }^{19}$ Recently, it was shown that the Grignard reaction with aliphatic aldehydes does not involve single electron transfer. ${ }^{20}$ These last results point at a clear preference for nucleophilic addition for aliphatic aldehyde and a possible competition between the radical and nucleophilic pathways for substrates with lower reduction potential, that is, aromatic or conjugated aldehydes or ketones.

While various aspects of the chemistry of Grignard species, including their formation, ${ }^{21-23}$ their structure, and their thermodynamics in solution, ${ }^{24-27}$ were addressed by computational approaches, the Grignard reaction itself has been the subject of only a few studies. ${ }^{28}$ In particular, in 2002 Yamazaki and Yamabe used density functional theory (DFT) calculations together with implicit solvation models to suggest that dinuclear Grignard moieties are more reactive in a nucleophilic addition than are monomeric species. ${ }^{29}$ Similar results were obtained with second-order Møller-Plesset perturbation theory together with implicit solvation models. ${ }^{30}$ Yamazaki and Yamabe suggested that a mechanism going through $\mathrm{Mg}-\mathrm{C}$ homolytic cleavage could be preferred in the case of bulky organic residues, for which the nucleophilic addition is sterically hindered. ${ }^{29}$

Recently, some of us carried out an ab initio molecular dynamics (AIMD) study of $\mathrm{CH}_{3} \mathrm{MgCl}$ in tetrahydrofuran (THF) to get insight on the role of the solvent in the Schlenk equilibrium. ${ }^{31}$ Among other findings, this study showed that the magnesium centers of the mononuclear and dinuclear species can accommodate a variable number of solvent molecules in their first coordination spheres and that the interchange of the methyl and chloride groups between the two magnesium centers is associated with a change in the solvation number. ${ }^{31}$ This study thus revealed that it was essential to allow a synergy between the solvent contribution and the chemical event at the $\mathrm{Mg}$ centers and to represent the associated solvent reorganization, an effect that cannot be properly described by a static approach.

The purpose of the present study is to use computational approaches to determine the factors that drive the Grignard reaction toward preferred pathways (in particular nucleophilic vs single electron transfer) in the presence of prototypical carbonyl substrates, as well as to elucidate the mechanistic details for each specific transformation. The employment of $a b$ initio molecular dynamics and enhanced-sampling methods in explicit solvent facilitates an unbiased exploration of the conformational space. In particular, it allows a thorough sampling of the solvation states of all organomagnesium species and a reliable description of solvent dynamics. Finally, state-of-the-art quantum-chemical calculations provide solid data to understand the factors that promote a single electrontransfer pathway.

\section{COMPUTATIONAL METHODS}

Ab Initio Molecular Dynamics Simulations. Simulation Protocol. The thermodynamically equilibrated structures of the Grignard reagent in THF in different protomeric and solvated forms were determined in a previous study. ${ }^{31}$ In this work, the initial geometry of each reactive complex was built starting from that of the respective Grignard reagent by replacing one THF coordinated to $\mathrm{Mg}$ with a substrate molecule. All systems were simulated in an orthorhombic periodic box of dimensions $25.2 \times 15.0 \times 15.0 \AA^{3}$, containing 41 THF molecules. The quantum-chemical problem was solved at the $\mathrm{DFT}^{32,33}$ level using the Perdew-Burke-Ernzerhof (PBE) exchange correlation (xc) functional. ${ }^{34}$ The Kohn-Sham orbitals were expanded over mixed Gaussian and plane-wave basis functions. The DZVP basis set for first and second row elements and a molecular optimized basis set for chlorine were employed. ${ }^{35}$ The auxiliary plane-wave basis set was expanded up to a 200 Ry cutoff. The core electrons were integrated out using pseudopotentials of the Goedecker-Teter-Hutter type (GTH). ${ }^{36}$ Dispersion forces were included using the D3 Grimme approximation. ${ }^{37}$ AIMD simulations were run over the ground-state potential energy surface, adopting a threshold for the energy gradient of $10^{-5}$ au as numerical convergence criterion for the electronic energy. The equations of motion were integrated employing the velocity Verlet algorithm ${ }^{38}$ with a time-step of 0.25 fs. Relaxation to the target temperature was first performed using a canonical sampling/velocity rescaling (CSVR) thermostat ${ }^{39}$ 


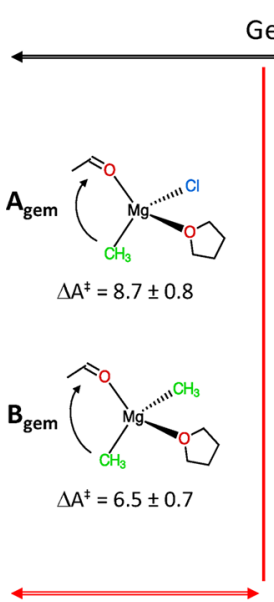

Mononuclear

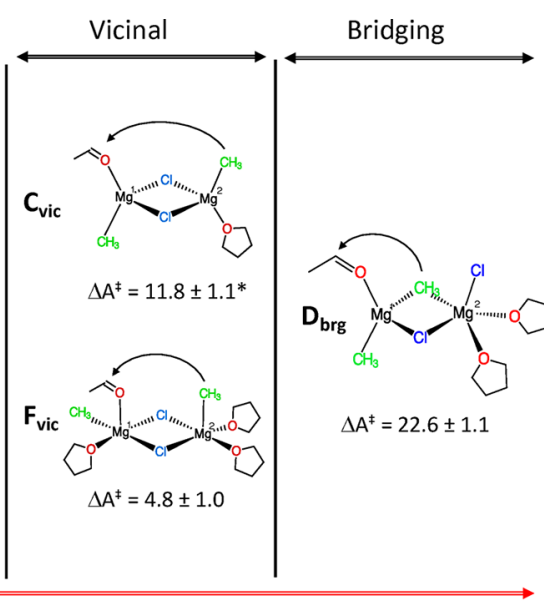

Dinuclear

Figure 2. Organomagnesium complexes considered as reactants for the polar mechanism, classified as a function of the relative positions of the substrate (ACA) and nucleophile (methyl group). The labels geminal, vicinal, and bridging describe the initial position of the reactive groups with respect to the $\mathrm{Mg}$ center(s). The activation free energies, $\Delta A^{\ddagger}$, defined as the difference in free energy between the TS and the related reactant species, are given in $\mathrm{kcal} \mathrm{mol}^{-1}$.

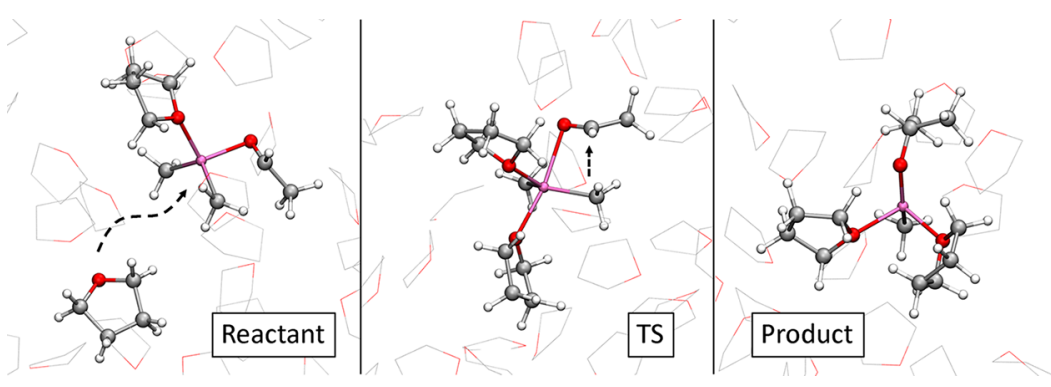

Figure 3. Geminal reaction for compound $\mathbf{B}_{\text {gem }}$. Representative geometries for the reactant, transition state, and product. The $\mathrm{Mg}$ atom and its ligands are represented as balls-and-sticks. Other solvating THF molecules are drawn as lines. The color codes are mauve for magnesium, red for oxygen, gray for carbon, and white for hydrogen.

with a time constant of $10 \mathrm{fs}$ until the temperature of the system oscillated around the target value. A Nosé-Hoover chain thermostat with a chain length of 3 and a time constant of 1 ps then was used for data production. ${ }^{40-42}$ Trajectory analysis was performed using the tools available in the VMD 1.9.2 package. $^{43}$

Polar Mechanism - Activation Energies. The activation barriers for the nucleophilic addition were estimated by constraint dynamics in the blue-moon ensemble ${ }^{44}$ using the distance between the methyl group and the carbonyl carbon as reaction coordinate $\lambda$. The constraint force $f(\lambda)$ was collected over independent AIMD runs at nine fixed values of $\lambda$ spaced by $0.2-0.1 \AA$. The average value of $f$ at each $\lambda$ point $\left(\langle f\rangle_{\lambda}\right)$ converged with steady mean values of $\sim 0.5 \mathrm{kcal}$ $\mathrm{mol}^{-1} \AA^{-1}$ within $\sim 2 \mathrm{ps}$ of simulations. The activation free energy $\Delta A^{\ddagger}$ was computed by trapezoidal integration of $\langle f\rangle_{\lambda}$ between $\lambda$ values corresponding to the reactant and the TS. This last point was identified as the value of $\lambda$ at which $\langle f\rangle_{\lambda}=0$. The work reports Helmholtz free energies as AIMD are performed at constant volume conditions.

Radical Formation Energy. The dissociation energy associated with the homolytic cleavage of the $\mathrm{Mg}$-methyl bond for different Grignard reagent/substrate complexes was estimated as the difference between the total energy of the reactant and that of the individual fragments. THF molecules directly bound to $\mathrm{Mg}$ were explicitly considered in the model, while the rest of the solvent was treated implicitly using a continuum dielectric model. ${ }^{45}$ The electronic problem was solved at the DFT level using the M06-2X xc functional ${ }^{46}$ and the $6-31+G(d, p)$ basis set. ${ }^{47}$ Calculations were performed using the Gaussian 09 package. ${ }^{48}$ The choice of the M06$2 \mathrm{X}$ functional was done after assessing the quality of different $\mathrm{xc}$ functionals in reproducing coupled-cluster (CC) data for the radical formation energy in a simplified model (Table S1). The reference energies were obtained using the CC singles and doubles (CCSD) approximation augmented by a perturbative treatment of triple excitations $(\operatorname{CCSD}(\mathrm{T}))^{49}$ with an energy convergence threshold of $10^{-9}$ hartree, using a cc-pVTZ basis set. ${ }^{50}$ The $\operatorname{CCSD}(\mathrm{T})$ calculations were carried out using the CFOUR package. ${ }^{51}$

\section{RESULTS AND DISCUSSION}

Polar Mechanism. Alkyl carbonyl substrates have been shown to prefer a nucleophilic pathway in their reaction with Grignard reagents. ${ }^{20}$ For this reason, we modeled the reaction of acetaldehyde (ACA hereafter) with $\mathrm{CH}_{3} \mathrm{MgCl}$ in THF. All forms of $\mathrm{CH}_{3} \mathrm{MgCl}$ identified in our previous study as stable species coexisting at thermal equilibrium in $\mathrm{THF}^{31}$ were considered as potential reactive systems after replacing one coordinated THF by ACA. ${ }^{31}$

Figure 2 shows the labels used throughout this work to identify the organometallic mononuclear and binuclear species and the associated possible pathways, which are characterized by the position of the reactive groups on the $\mathrm{Mg}$ centers. The pathway is called geminal if the two groups are on the same magnesium atom and is called vicinal if they are on two different magnesiums. Finally, a pathway where the methyl group bridges the two magnesium atoms was also considered.

Reaction with Geminal and Bridging Groups. Both mononuclear and dinuclear $\mathrm{Mg}$ species can be associated with geminal pathways. Of the two mononuclear systems, $\mathbf{B}_{\mathrm{gem}}$ gives the energetically lowest transition state (TS), with an 
$\Delta A^{\ddagger}$ of $6.5 \pm 0.7 \mathrm{kcal} \mathrm{mol}^{-1}$ (Figure 2). The pathway starting from $\mathrm{CH}_{3} \mathrm{MgCl}\left(\mathrm{A}_{\text {gem }}\right)$ has a higher lying TS with $\Delta A^{\ddagger}=8.7 \pm$ $0.8 \mathrm{kcal} \mathrm{mol}^{-1}$. $\mathbf{E}_{\mathrm{gem}}$ is the most reactive dinuclear complex via a geminal pathway. This species is a variant of $\mathbf{B}_{\text {gem }}$ in which the coordinated THF is replaced by a Cl-coordinated $\mathrm{MgCl}_{2}$ (THF) $)_{2}$ moiety. It is thus not surprising that the TSs associated with $\mathbf{B}_{\text {gem }}$ and $\mathbf{E}_{\text {gem }}$ have similar activation energies. However, our earlier study on the Schlenk equilibrium ${ }^{31}$ indicated that $\mathbf{E}_{\text {gem }}$ is less abundant than $\mathbf{B}_{\text {gem }}$. This suggests that $\mathbf{E}_{\text {gem }}$ may contribute only marginally to the formation of the product. Species $\mathbf{C}_{\text {gem }}$ and $\mathbf{D}_{\text {gem }}$ are instead characterized by a significantly higher activation energy (both around $13 \mathrm{kcal}$ $\mathrm{mol}^{-1}$, Figure 2). Finally, the bridging methyl group is unlikely to act as a nucleophile, as indicated by the high activation energy of $\Delta A^{\ddagger}=22.6 \mathrm{kcal} \mathrm{mol}^{-1}$ for $\mathbf{D}_{\text {brd }}$. As could be expected, a nucleophile is less reactive at a bridging than at a terminal position.

Structural Features of the Geminal Reaction. The reaction in $\mathbf{B}_{\text {gem }}$ is used here as a representative case to describe the structural details of the geminal pathway (Figure 3). In THF, $\mathrm{Mg}\left(\mathrm{CH}_{3}\right)_{2}$ forms $\mathrm{Mg}\left(\mathrm{CH}_{3}\right)_{2}(\mathrm{THF})_{2}$. This complex has a distorted tetrahedral structure with an angle of $135 \pm 9^{\circ}$ between the two $\mathrm{Mg}-\mathrm{CH}_{3}$ bonds, larger than that formed by the two $\mathrm{Mg}-\mathrm{O}$ bonds $\left(92 \pm 8^{\circ}\right.$, Figure S1). Replacement of one THF molecule by ACA yields compound $\mathbf{B}_{\text {gem }}$, which also has a distorted tetrahedral structure with obtuse $\mathrm{CH}_{3}-\mathrm{Mg}-\mathrm{CH}_{3}$ and $\mathrm{O}(\mathrm{ACA})-\mathrm{Mg}-\mathrm{O}$ (THF) angles (153 \pm $9^{\circ}$ and $137 \pm 9^{\circ}$, respectively) and an $\mathrm{O}(\mathrm{ACA})-\mathrm{Mg}-\mathrm{CH}_{3}$ angle of $92 \pm 11^{\circ}$ (Figure S2). This arrangement leads to a close proximity between the nucleophilic and the electrophilic groups.

In the reactant, the methyl group is tightly bound to $\mathrm{Mg}$ with an average $\mathrm{Mg}-\mathrm{C}$ bond distance of $2.15 \pm 0.08 \AA$. In contrast, $\mathrm{ACA}$ is more loosely bound, with a $\mathrm{Mg}-\mathrm{O}$ distance of $2.4 \pm 0.2 \AA$, which is longer than the Mg-THF distance of $2.2 \pm 0.1 \AA$. The $\mathrm{Mg}$ atom lies in the plane of ACA with a $\mathrm{C}-\mathrm{O}-\mathrm{Mg}$ angle of $118 \pm 9^{\circ}$, indicating that the magnesium ion interacts with the two lone pairs of the carbonyl oxygen.

At the TS, the addition of one THF molecule from the bulk solvent leads to a complex with a distorted trigonalbipyramidal structure where ACA and the approaching THF reside at the apical sites with an average $\mathrm{O}(\mathrm{ACA})-\mathrm{Mg}-\mathrm{O}$ (THF) angle of $164 \pm 10^{\circ}$ (Figure 4). Reaching the TS also requires a rotation of ACA around the $\mathrm{C}=\mathrm{O}$ axis to establish the interaction of the nucleophile with the carbonyl $\pi$ system (Figure 4). The formation of the bond between the two carbon atoms is also promoted by a slight bending of ACA toward the methyl group, indicated by a decrease in the $\mathrm{C}-\mathrm{O}-\mathrm{Mg}$ angle to a value of $97 \pm 3^{\circ}$. On the contrary, the $\mathrm{CH}_{3}-\mathrm{Mg}-\mathrm{O}(\mathrm{ACA})$ angle of $\left(93 \pm 3^{\circ}\right)$ remains similar to that in $\mathbf{B}_{\text {gem }}$.

The geminal reaction occurs via a concerted mechanism, with the TS showing partial formation and cleavage of the $\mathrm{C}-\mathrm{C}$ and $\mathrm{Mg}-\mathrm{CH}_{3}$ bonds, respectively. An informative parameter is the direction of the $C_{3}$ axis of the methyl group, which is significantly displaced away from the $\mathrm{CH}_{3}-\mathrm{Mg}$ direction, but not yet aligned to the new $\mathrm{C}-\mathrm{C}$ direction $\left(\phi_{1}\right.$, $\phi_{2}$ angles in Figure 4). The four atoms involved in the bond rearrangement are coplanar (Figure 4 ), with a $\mathrm{CH}_{3} \cdots \mathrm{C}-\mathrm{O}$ angle of attack of $107 \pm 4^{\circ}$, consistent with expected values for a nucleophilic addition to a carbonyl group. ${ }^{52,53}$ The fourcentered TS has a reactant-like geometry, with a relatively long $\mathrm{C} \cdots \mathrm{C}$ bond distance of $2.55 \AA$ and the ACA carbon with an

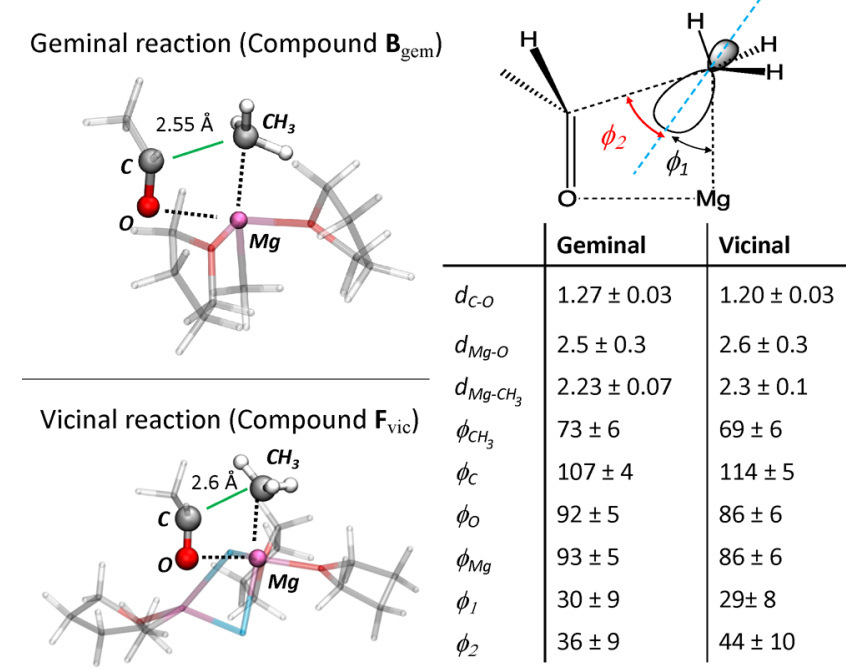

Figure 4. Transition state structures of the geminal and vicinal reactions $\left(\mathbf{B}_{\mathrm{gem}}, \mathbf{F}_{\mathrm{vic}}\right)$. Left: Evidence of the structural similarity of the two TSs. Balls-and-sticks are used to represent the reacting moiety, while the rest of the system is drawn as transparent cylinders. THF molecules not bound to $\mathrm{Mg}$ are not shown. The green line marks the incipient $\mathrm{C}-\mathrm{CH}_{3}$ bond and its associated distance. Top right: Schematic definition of the angles formed by the $C_{3}$ axis of the nucleophile methyl group. Bottom right: Distances and angles formed by the atoms involved in the four-center TS. Distances are reported in angstroms, and angles are in degrees. $\phi_{\mathrm{X}}$ is the angle at the vertex $\mathrm{X}$ in the four-member ring (top right panel). The color code is as in Figure 3.

out-of-plane angle (defined by the improper $\mathrm{CH}_{3}-\mathrm{C}-\mathrm{O}-\mathrm{H}$ dihedral angle) of $161 \pm 7^{\circ}$, closer to the ideal value of $180^{\circ}$ for an $\mathrm{sp}^{2}$ atom than $120^{\circ}$ for an $\mathrm{sp}^{3}$ one. Both ACA and the methyl groups are slightly farther away from the $\mathrm{Mg}$ center than in the reactant geometry, as indicated by the $\mathrm{Mg}-\mathrm{CH}_{3}$ and $\mathrm{Mg}-\mathrm{O}$ distances of $2.23 \pm 0.07$ and $2.5 \pm 0.3 \AA$, respectively.

In the relaxed product $\mathrm{CH}_{3} \mathrm{Mg}\left(\mathrm{OCH}\left(\mathrm{CH}_{3}\right)_{2}\right)(\mathrm{THF})_{2}$, the $\mathrm{Mg}$ atom is again tetracoordinated, with the $\mathrm{CH}_{3}-\mathrm{Mg}-\mathrm{O}$ (isopropanol) and $\mathrm{O}(\mathrm{THF})-\mathrm{Mg}-\mathrm{O}(\mathrm{THF})$ angles similar to those in the reactant geometry $\left(134 \pm 8^{\circ}\right.$ and $93 \pm 7^{\circ}$, respectively, Figure S3).

The coordination of the solvent assists the heterolytic cleavage of the $\mathrm{Mg}-\mathrm{CH}_{3}$ bond by donating electron density to the $\mathrm{Mg}$ atom. It appears that the reactivity of the $\mathrm{Mg}$ complex increases when the coordinated ligands are better electron donors and/or more ligands coordinate to the magnesium center. These electron-donating ligands screen the charge on the $\mathrm{Mg}$ center, making the nucleophilic $\mathrm{CH}_{3}$ a better leaving group. In particular, $\mathrm{Mg}\left(\mathrm{CH}_{3}\right)_{2}$ is found to be slightly more reactive than $\mathrm{CH}_{3} \mathrm{MgCl}$, which is consistent with the known greater electron-donating ability of a methyl group relative to chloride in these magnesium complexes as it also appeared in our previous study. ${ }^{31}$ Moreover, the slightly higher reactivity of the mononuclear over dinuclear species correlates to the fact that terminal ligands are better electron donors than are the bridging ones.

Reaction with Vicinal Groups. The vicinal reaction was studied for species $\mathbf{C}_{\text {vic }}$ and $\mathbf{F}_{\text {vic }}$ (Figure 2). The most solvated dinuclear complex $\mathbf{F}_{\mathrm{vic}}$, with two pentacoordinated $\mathrm{Mg}$ atoms, has an activation energy for the $\mathrm{C}-\mathrm{C}$ bond formation of $\Delta A^{\ddagger}$ $\sim 4.8 \mathrm{kcal} \mathrm{mol}^{-1}$. This is the lowest activation energy that has 

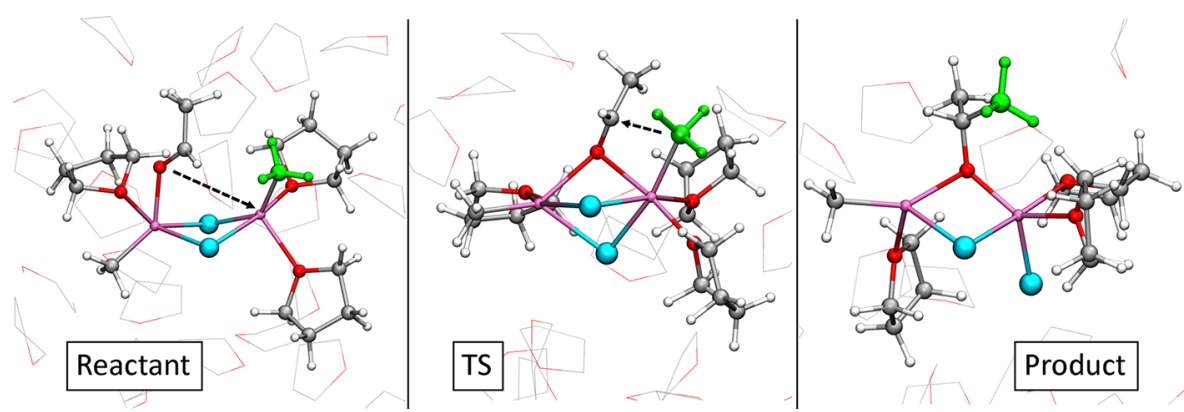

Figure 5. Vicinal reaction for $\mathbf{F}_{\text {vic }}$. Representative geometries for the reactant, transition state, and product. $\mathrm{The} \mathrm{Mg}$ atoms $\left(\mathrm{left} \mathrm{Mg}^{1}\right.$, right $\left.\mathrm{Mg}^{2}\right)$ and first coordination sphere ligands are represented as balls-and-sticks. Other solvating THF molecules are drawn as lines. The color code is cyan for chlorine and green for the nucleophilic methyl, while the other elements are colored as in Figure 3.



Figure 6. Red: Activation energies of all Grignard species derived from $\mathrm{CH}_{3} \mathrm{MgCl}$ in THF solution when reacting with acetaldehyde. Blue: Relative free energies of the species involved in the Schlenk equilibrium (data from ref 31). The green box highlights the intrinsically most reactive species identified in this work.

been calculated for all mononuclear and dinuclear species considered in this study. According to our previous study, $\mathbf{F}_{\text {vic }}$ is also one of the most abundant species in the Schlenk equilibrium, with a free energy of only $1.3 \mathrm{kcal} \mathrm{mol}^{-1}$ higher than that of the most stable dichloro-bridged compound $\left(\mathbf{C}_{\text {vic }}\right) \cdot{ }^{31} \mathbf{F}_{\text {vic }}$ is therefore a key contributor to the formation of product by way of the nucleophilic addition. The most reactive species has ACA and the nucleophilic methyl group initially coordinated to two distinct magnesium atoms $\left(\mathrm{Mg}^{1}\right.$ and $\mathrm{Mg}^{2}$, respectively) and thus rather far from each other. Considerable structural reorganization is occurring on the way to the transition state. At the TS, characterized by a C...C distance of 2.6 $\AA$, ACA enters in the coordination sphere of $\mathrm{Mg}^{2}$ while still interacting with $\mathrm{Mg}^{1}$, as shown by the similar $\mathrm{Mg}^{1}-\mathrm{O}$ and $\mathrm{Mg}^{2}-\mathrm{O}$ distances of $2.12 \pm 0.07$ and $2.27 \pm 0.19 \AA$, respectively (Figure 4). Consequently, $\mathrm{Mg}^{1}$ retains a pentacoordinated structure at the TS. In parallel, $\mathrm{Mg}^{2}$ acquires an octahedral coordination (Figure 5), with an $\mathrm{O}$ (ACA) $-\mathrm{Mg}^{2}-\mathrm{CH}_{3}$ angle between the two reacting cis-ligands of $\sim 90^{\circ}$.

The four-center TS shares strong similarities with that found for the geminal reaction, with an elongated $\mathrm{Mg}^{2}-\mathrm{CH}_{3}$ bond $(\sim 2.3 \AA)$, a methyl lone-pair axis twisted $\sim 30^{\circ}$ away from the
$\mathrm{Mg}^{2}-\mathrm{CH}_{3}$ direction, and a favorable $\mathrm{CH}_{3} \cdots \mathrm{C}=\mathrm{O}$ angle ${ }^{52,53}$ of $114 \pm 10^{\circ}$ (Figure 4). Also, in this case, the ACA carbon essentially retains an $\mathrm{sp}^{2}$ hybridization at the transition, similar to that found earlier for $\mathbf{B}_{\text {gem }}$.

Relaxation from the transition state yields a product where the alcoholate bridges the two magnesium atoms (Figure 5). The chlorine atom that is anti to the nucleophilic $\mathrm{CH}_{3}$ in the reactant leaves its bridging position to occupy a terminal site at $\mathrm{Mg}^{2}$. Reorganization of the bridging ligands yields the final product where $\mathrm{Mg}^{1}$ is tetracoordinated and $\mathrm{Mg}^{2}$ is pentacoordinated (Figure 5).

The significantly higher activation energy $\left(\Delta A^{\ddagger} \sim 13.0 \mathrm{kcal}\right.$ $\mathrm{mol}^{-1}$ ) required for the most stable dinuclear species $\mathrm{C}_{\mathrm{vic}}$ (Figure 2) to undergo the nucleophilic reaction highlights the role of the coordinated solvent. Both $\mathbf{F}_{\mathrm{vic}}$ and $\mathbf{C}_{\mathrm{vic}}$ have two bridged chloride ligands and a terminal methyl group on each magnesium atom. Thus, the difference between them resides in the number of THF solvent molecules coordinated to each magnesium, the more reactive species being more solvated. The least solvated $\mathbf{C}_{\text {vic }}$ is in fact a rigid species in which ACA cannot approach the nucleophilic methyl group coordinated to the other magnesium. Interestingly, the calculations indicate that an additional THF binds $\mathbf{C}_{\mathrm{vic}}$ on the ACA-bonded 


\begin{tabular}{|c|c|c|c|c|c|}
\hline \multirow[t]{2}{*}{ Substrate } & \multicolumn{2}{|c|}{$\begin{array}{l}\text { Bond dissociation energy (BDE) } \\
{\left[\mathrm{kcal} \mathrm{mol}^{-1}\right]}\end{array}$} & \multicolumn{2}{|c|}{ Integrated spin density on selected atoms } & \multirow{2}{*}{$\begin{array}{l}\text { Spin density map } \\
\qquad(n=2)\end{array}$} \\
\hline & $\mathrm{n}=1$ & $\mathrm{n}=2$ & $n=1$ & $n=2$ & \\
\hline $\mathrm{CH}_{3}$ & 51.3 & 37.9 & $\begin{array}{c}C=0.53 \\
O=0.23 \\
M g=0.06\end{array}$ & $\begin{array}{c}C=0.59 \\
O=0.21 \\
M g=0.01\end{array}$ & \\
\hline$=0$ & 45.1 & 33.4 & $\begin{array}{c}C=0.61 \\
O=0.20 \\
M g=0.01\end{array}$ & $\begin{array}{c}C=0.55 \\
O=0.21 \\
M g=0.01\end{array}$ & \\
\hline$=0$ & 35.3 & 24.8 & $\begin{array}{c}C=0.66 \\
O=0.16 \\
M g=0.01\end{array}$ & $\begin{array}{c}C=0.65 \\
O=0.15 \\
M g=0.00\end{array}$ & \\
\hline
\end{tabular}

Figure 7. $\mathrm{Mg}-\mathrm{CH}_{3} \mathrm{BDE}$ and spin-density localization (in fractions of $e$ ) for $\mathrm{MgCl}(\mathrm{Sub})(\mathrm{THF})_{n} \mathrm{CH}_{3}(\mathrm{Sub}=$ substrate). The green wire-frame shows the isosurface of the spin density map at a value of 0.0065 au.

magnesium prior to reaching the transition state. This event occurs when the carbon-carbon distance is $\sim 4 \AA$, still more than $1 \AA$ longer than at the TS. The formation of a pentacoordinated species on the ACA-coordinated $\mathrm{Mg}$ facilitates the migration of ACA toward the methyl bearing $\mathrm{Mg}$, enabling the reaction. The solvent thus appears to be a key factor in the reaction by increasing the flexibility of the $\mathrm{Mg}$ complex, thus lowering the energy needed for getting the electrophile and nucleophile close to each other (Figure 5).

A previous work proposed that the Grignard reaction would occur starting from a dinuclear structure characterized by a single bridging chloride and two methyl groups each bound to a different $\mathrm{Mg}$ atom. ${ }^{30}$ Nonetheless, the calculations showed that this complex was not stable in solution and it rapidly evolved into a dichloro-bridged structure. This is consistent with what has been already observed in our previous work: the monochloride bridged structures were not associated with freeenergy minima, but they corresponded to the transition states during the transmetalation step in the Schlenk equilibrium. ${ }^{31}$ Because of their instability, and the already high reactivity of more stable compounds, it is unlikely that such moieties play a significant role in the Grignard reaction.

Role of the Schlenk Equilibrium in the Nucleophilic Grignard Reaction. Figure 6 compiles the activation energies of the reaction pathways considered in this work, together with the relative stability of the various organomagnesium species involved in the Schlenk equilibrium as previously derived. ${ }^{31}$

The Schlenk equilibrium is driven by the dynamics of the coordinating solvent in the Grignard reagent dimers, ${ }^{31}$ and its mechanism shares structural similarities with the vicinal pathway. Specifically, in the Schlenk equilibrium, the increased coordination of the solvent assists the displacement of the ionic ligands from the terminal to the bridging positions by increasing the flexibility of the organomagnesium complex. In the Grignard reaction, the most reactive structure $\mathbf{F}_{\text {vic }}$ has two pentacoordinated $\mathrm{Mg}$ centers, $\mathrm{Mg}^{1}$ with one THF and ACA, and $\mathrm{Mg}^{2}$ with two THF molecules. This high coordination of the two Mg centers facilitates the shift of ACA from a terminal to a bridging position while minimizing the motion of the other ligands (Figure 5). At the bridging position, the electrophilicity of ACA is significantly increased. In the same time, the coordination of $\mathrm{Mg}^{2}$ augments from five to six, which in turn helps in the departure of the nucleophilic methyl group. Thus, through different coordination to the Mg centers, the solvent has contributed to make the substrate ACA more electrophilic and the methyl group more nucleophilic. The entropic factor also favors the vicinal reaction in this dinuclear complex relative to the most favorable geminal reaction. Indeed, in the latter, the coordination of an additional THF is necessary at the transition state, while in the former, there is no need for a THF from the bulk of the solvent to enter the coordination sphere of any of the two magnesium centers. The dinuclear complex needs only to modify the position of the various ligands and coordinated solvent to reach the transition state. Thus, cleaving the terminal $\mathrm{Mg}^{2}-\mathrm{CH}_{3}$ bond is accompanied by the displacement of a bridging chloride to a terminal position to ensure appropriate anionic coordination at $\mathrm{Mg}^{2}$. Two coordinating THF solvent molecules are sufficient to stabilize the pentacordinated $\mathrm{Mg}^{2}$ linked also to a terminal $\mathrm{Cl}$ and to the bridging alcoholate and chloride ligands.

In practice, the Grignard reaction can be viewed as a variant of the Schlenk equilibrium where the nonreactive solvent is replaced by an unsaturated substrate that becomes a strong electrophile when entering the coordination sphere of $\mathrm{Mg}$. The energetically easy exchange between terminal and bridging ligands under the assistance of the solvent is at the heart of this chemistry.

While the vicinal pathway through the dinuclear $\mathrm{Mg}$ complex $\left(F_{\text {vic }}\right)$ looks intrinsically the most reactive, the geminal pathway should nevertheless be considered as a competitive alternative. In particular, mononuclear species have activation energies only slightly higher than that of the most reactive dinuclear complex. Thus, the preferred pathway for the Grignard reaction would be determined by the relative abundance of the mononuclear and dinuclear compounds. Likely, several forms may be active simultaneously in the complex mixture formed by the Grignard reagent in solution. It should be kept in mind that the Grignard reagent forms 

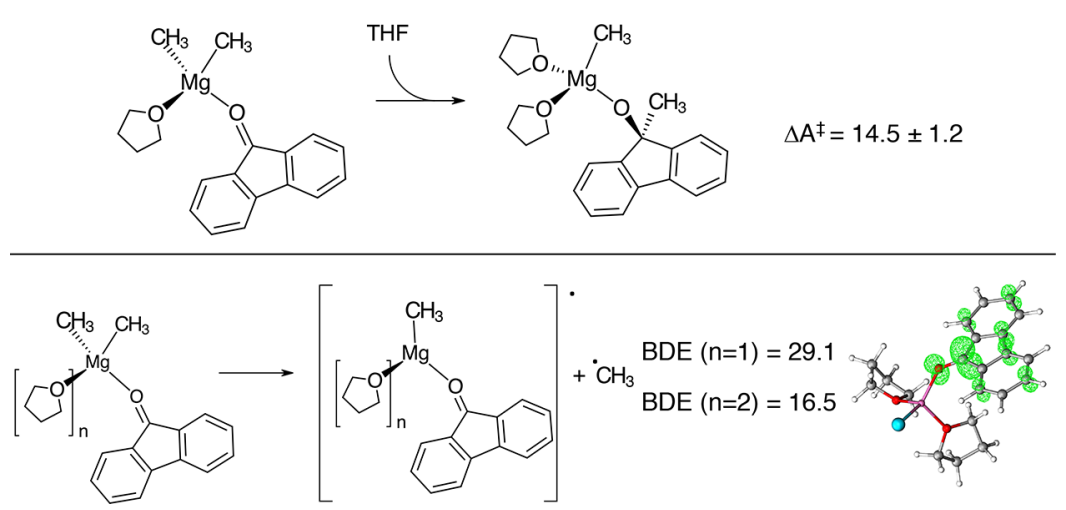

Figure 8. Energetics of the Grignard reaction mechanisms for fluorenone. Top panel: Activation free energy of the nucleophilic addition with $\mathrm{Mg}\left(\mathrm{CH}_{3}\right)_{2}$. Bottom panel: Bond dissociation energy. All energy values are in $\mathrm{kcal} \mathrm{mol}^{-1}$. On the right is the distribution of the spin density in $\mathrm{Mg}\left(\mathrm{CH}_{3}\right)$ (fluorenone) $\mathrm{THF}_{2}: 33 \%$ of the unpaired electron localizes on the carbonyl carbon, $16 \%$ on the carbonyl oxygen, and $45 \%$ on the remaining $\pi$ system.

clusters whose nature and relative abundance depend on the solvent and the halide ligand in a nontrivial manner. ${ }^{6,54}$

Our findings stress the importance of an unbiased exploration of the conformational space and, in particular, of the explicit treatment of the solvent. In fact, the solvent is a direct player in all reactive pathways identified in the present work, in particular by structurally and dynamically affecting the coordination sphere of $\mathrm{Mg}$. This is particularly relevant for the determination of the free energy barrier in the geminal reaction where the $\mathrm{C}-\mathrm{C}$ bond formation, associated with a cleavage of the $\mathrm{Mg}-\mathrm{CH}_{3}$ bond, occurs with the assistance of an incoming solvent entering the coordination sphere of $\mathrm{Mg}$. This ensures that the magnesium is coordinated to at least four ligands as it was found to be required. ${ }^{31}$ The direct role of the solvent in modulating the reaction is the main reason for the discrepancies found with the preceding studies by Yamazaki and Yamabe ${ }^{29}$ and by Mori and Kato. ${ }^{30}$ In particular, our study contrasts with their hypothesis that mononuclear species may be significantly less able to promote the Grignard reaction. In fact, such divergences arise because of, in these previous investigations, a fixed number of ligands at the magnesium centers, in particular disregarding the dynamic role of the solvent and its capability of entering in the coordination sphere during the reaction.

Radical Mechanism. Quantum-chemical calculations indicate that the homolytic cleavage of the $\mathrm{Mg}-\mathrm{CH}_{3}$ bond in the solvated Grignard reagent $\mathrm{CH}_{3} \mathrm{MgCl}(\mathrm{THF})_{n}$ requires a high energy of $66.6 \mathrm{kcal} \mathrm{mol}^{-1}$ for $n=2$, which is not lowered by increasing solvation $\left(66.4 \mathrm{kcal} \mathrm{mol}^{-1}\right.$ for $\left.n=3\right)$. The calculated values compare well with those determined experimentally for $\mathrm{CH}_{3} \mathrm{MgBr}$ in diethyl ether ${ }^{55}(\sim 61 \mathrm{kcal}$ $\mathrm{mol}^{-1}$ ), suggesting a marginal influence of the halide and solvent on the $\mathrm{Mg}-\mathrm{CH}_{3}$ bond dissociation energy (BDE).

The high value of the $\mathrm{Mg}-\mathrm{CH}_{3} \mathrm{BDE}$ indicates that alkyl radicals cannot be formed in pure solutions of the Grignard reagent. $^{56}$ Indeed, the experiment reports the presence of organic radicals only when electrophilic substrates of low reduction potential are present. ${ }^{14}$ This suggests that the substrate may promote the homolytic cleavage.

The $\mathrm{M}-\mathrm{CH}_{3}$ BDEs were thus calculated for complexes with coordinated substrates. Figure 7 reports the $\mathrm{Mg}-\mathrm{CH}_{3} \mathrm{BDE}$ for substrates of decreasing reduction potential (acetaldehyde $>$ formaldehyde > carbonyl difluoride) with one or two coordinated THF molecules. Indeed, the nature of the coordinated substrate influences significantly the $\mathrm{Mg}-\mathrm{CH}_{3}$
BDE, as shown by its decrease from acetaldehyde $(37.9 \mathrm{kcal}$ $\mathrm{mol}^{-1}$ ) to carbonyl difluoride $\left(24.8 \mathrm{kcal} \mathrm{mol}^{-1}\right.$ ) (Figure 7 , values for two bound THFs). The strong influence of the substrate on the $\mathrm{BDE}$ can be rationalized by considering the localization of the unpaired electron on the organomagnesium radical product. As shown in Figure 7, the electron spin density mostly resides on the substrate carbonyl group and not on the $\mathrm{Mg}$ atom regardless of the nature of the substrate and the number of bound THFs. Consequently, the BDE correlates to the energy of the singly occupied $\pi^{*}(\mathrm{CO})$ Kohn-Sham orbital in the radical product, as indicated by the corresponding orbital energies of $-0.18057,-0.18846$, and -0.25703 au for acetaldehyde, formaldehyde, and carbonyl difluoride, respectively.

The role of a low-lying empty $\pi^{*}$ orbital at the substrate in the stabilization of the radical species rationalizes the high BDE values in the absence of any coordinated carbonyl substrate. In fact, in the case of $\mathrm{MgCl}(\mathrm{THF})_{2}^{\bullet}$ radical, the unpaired electron remains located on $\mathrm{Mg}$, with about $0.8 e$ of the spin density. The previous analysis also explains why the degree of solvation has a stronger influence for the BDE in the substrate-bound species than in the substrate-free Grignard reagent. In the presence of the substrate, the delocalization of the unpaired electron produces an effective increase of the electrostatic charge on the $\mathrm{Mg}$ atom, which can be stabilized by additional electron-donating ligands. Thus, increased solvation decreases the $\mathrm{Mg}-\mathrm{CH}_{3}$ BDE. The effect of the solvent depends only slightly on the nature of the coordinated substrate because the stabilization is from 13 to $10 \mathrm{kcal} \mathrm{mol}^{-1}$ for acetaldehyde to carbonyl difluoride, respectively. For a similar reason, $\mathrm{Mg}\left(\mathrm{CH}_{3}\right)_{2}$ promotes the homolytic dissociation of the methyl radical more than does $\mathrm{CH}_{3} \mathrm{MgCl}$, with a decrease in the $\mathrm{BDE}$ by roughly $10 \%$.

Nucleophilic Attack versus Homolytic Cleavage: The Case of Fluorenone. The quantum-chemical calculations of the $\mathrm{Mg}-\mathrm{CH}_{3} \mathrm{BDE}$ presented here show that the formation of radical species by cleavage of the $\mathrm{Mg}-\mathrm{CH}_{3}$ bond is unlikely in the absence of a coordinated substrate with a low-lying empty orbital. This observation accounts for previous conclusions by Otte and Woerpel ${ }^{20}$ that the Grignard reaction does not proceed via a radical mechanism with alkyl aldehydes and ketones. The same finding is also consistent with the experimental evidence that a radical mechanism is often preferred for aromatic ketones and, in particular, for benzophenone and fluorenone. ${ }^{8-15}$ 
To evaluate the competition between the radical and nucleophilic addition pathways in aromatic substrates, we considered the case of the fluorenone. The calculations were carried out with monomeric $\operatorname{Mg}\left(\mathrm{CH}_{3}\right)_{2}$. This form of the Grignard reagent was selected because it is only slightly less reactive than the most reactive dinuclear complex, while it allows faster $\mathrm{ab}$ initio $\mathrm{MD}$ simulations.

The $\mathrm{Mg}-\mathrm{CH}_{3} \mathrm{BDE}$ in $\mathrm{CH}_{3} \mathrm{MgCl}$ (fluorenone)(THF) $)_{2}$ is $16.5 \mathrm{kcal} \mathrm{mol}^{-1}$, a value more than $20 \mathrm{kcal} \mathrm{mol}^{-1}$ smaller than that for ACA. Such a drastic lowering of the BDE is associated with a significant delocalization of the unpaired electron over the extended $\pi$ system of fluorenone (Figure 8). In particular, the spin density surrounding the carbonyl carbon integrates to only $0.5 e$, as compared to values larger than $0.8 e$ for the other substrates (Figure 7), with the rest of the spin density being distributed on the conjugated aromatic ring (Figure 8). Considering an entropic contribution to the free energy $(-T \Delta S)$ for a bond dissociation on the order of $10 \mathrm{kcal} \mathrm{mol}^{-1}$, the formation of a methyl radical would reach an overall free energy cost of only $\sim 6 \mathrm{kcal} \mathrm{mol}^{-1}$, which is in the same range of the most favorable free energy barriers for the nucleophilic addition mechanism with ACA.

Interestingly, $\mathrm{ab}$ initio $\mathrm{MD}$ simulations reveal that fluorenone is significantly less reactive than ACA via the nucleophilic pathway. For $\mathrm{Mg}\left(\mathrm{CH}_{3}\right)_{2}$ (fluorenone)(THF), we estimated an activation energy of $14.5 \pm 1.2 \mathrm{kcal} \mathrm{mol}^{-1}$ (Figure $8)$, a value around $8 \mathrm{kcal} \mathrm{mol}^{-1}$ higher than that for ACA.

The TS for the nucleophilic addition to fluorenone has structural features similar to those for ACA, as indicated by a C...C bond distance of $2.5 \AA$, a C out-of-plane angle of $164 \pm$ $4^{\circ}$, and an approach angle of $106 \pm 4^{\circ}$. However, the geometries of the reactant states are significantly different in the two species. For ACA, the $\mathrm{Mg}-\mathrm{CH}_{3}$ and $\mathrm{C}=\mathrm{O}$ bonds in the reactant state are essentially eclipsed, as shown by a $\mathrm{CH}_{3}-\mathrm{Mg}-\mathrm{O}-\mathrm{C}$ dihedral angle of $14 \pm 15^{\circ}$ (Figure 9).

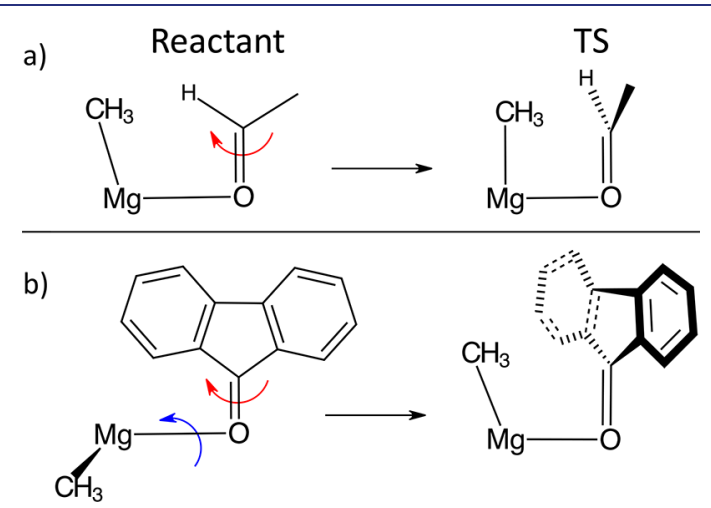

Figure 9. Structural reorganization from (left) reactant to (right) transition state in the nucleophilic pathway for (top) ACA and (bottom) fluorenone. The $\mathrm{CH}_{3}-\mathrm{Mg}-\mathrm{O}-\mathrm{C}$ dihedral angle (corresponding to the blue arrow) is $14 \pm 15^{\circ}$ for ACA and $114 \pm 30^{\circ}$ for fluorenone.

Therefore, a rotation of the ACA around the $\mathrm{C}=\mathrm{O}$ axis by $\sim 90^{\circ}$ is the main structural change required to reach the TS (Figure 9). For fluorenone, the bulky aryl group precludes an eclipsed conformation for the $\mathrm{Mg}-\mathrm{CH}_{3}$ and $\mathrm{C}=\mathrm{O}$ bonds, as indicated by an average $\mathrm{CH}_{3}-\mathrm{Mg}-\mathrm{O}-\mathrm{C}$ dihedral of $114 \pm$ $30^{\circ}$ (Figure 9). Consequently, in this case, an additional rotation around the $\mathrm{Mg}-\mathrm{O}$ bond is required to reach the TS. This suggests that the higher barrier calculated in the case of fluorenone originates in good part from a larger structural reorganization going from reactant to TS.

The present calculations help in understanding why the radical mechanism was observed with substrates characterized by a low reduction potential. Interestingly, such substrates are often bulky due to the presence of aryl groups and other conjugated substituents. These large groups may thus require larger structural rearrangement on the way to the TS for the nucleophilic addition, which can further disfavor such a mechanism against the radical one, as shown in the representative case of fluorenone.

\section{CONCLUSIONS}

The activation of both the nucleophilic and the radical mechanisms depends in a complex way on the nature of the substrate, on its binding to the $\mathrm{Mg}$ center, and on solvent dynamics. The combination of these subtle effects is the cause of the difficulties in determining and predicting the preferred pathways for the Grignard reaction.

The nucleophilic reaction occurs between the substrate and the nucleophile, which are both in the coordination sphere of $\mathrm{Mg}$ centers. Several organomagnesium species that coexist at thermal equilibrium in solution can promote the nucleophilic reaction with similar activation energies. This implies that several pathways involving different forms of the Grignard reagent may occur in parallel. The number of $\mathrm{Mg}$ atoms in the $\mathrm{Mg}$ species does not appear to influence significantly its reactivity because the two most reactive species with very similar activation energies are a dinuclear and a mononuclear compound. Likewise, similar activation energies are found when the substrate and the nucleophile are initially coordinated on the same or on nearby $\mathrm{Mg}$ atoms.

The solvent plays an essential role in the reaction. More solvated $\mathrm{Mg}$ species are more reactive. This seems to be due to the higher flexibility of the entire $\mathrm{Mg}$ species, which favors the structural reorganization from the reactant to the transition state. In less solvated species, additional coordination of solvent molecules coming from the bulk is still needed to promote the reaction, but the associated entropic cost makes these species less reactive. Thus, in all pathways, the solvent should be considered as one of the reactants. Similar effects probably apply in numerous organometallic reactions notably involving alkali, alkali-earth metals, and related lanthanide complexes, which are all known to be highly sensitive to solvent effects.

Like for the nucleophilic addition, the radical mechanism is strongly dependent on the coordination of the $\mathrm{Mg}$ center. The pure Grignard reagent is unlikely to release an organic radical even if heavily solvated. However, when one of the coordinated ligands is a substrate with a low-lying empty $\pi$ orbital and when the solvation is high, the $\mathrm{Mg}$-carbon bond breaks much more easily. Interestingly, the substituents able to lower the reduction potential of the substrate are often rather bulky, which in turn disfavors the nucleophilic pathway. The combination of electronic effects stabilizing the radical species and steric hindrance hampering the nucleophilic addition explains why a radical pathway has been observed with substrates like fluorenone or benzophenone but not with benzaldehyde.

The coexistence of multiple species in rapid exchange due to the Schlenk equilibrium and the evidence that the activation energy range of all possible reactions is relatively modest indicate that the Grignard reaction should not be described by 
an individual process. Instead, it should rather be thought of as an ensemble of transformations that can occur simultaneously in solution. It is likely that improvements of the Grignard reaction, for example, by alkali ${ }^{7,57}$ or copper salt additives, ${ }^{58,59}$ occur by interference with one or more of the possible pathways. In fact, the determination of all possible reaction pathways for the Grignard reaction and the key factors regulating them establishes the foundation for rational improvements of this process.

In this respect, it is noticeable that most reactive dinuclear species found in this study share strong similarities with the two-metal ion mechanism universally found in nature in the general class of catalytic RNA or metalloendonuclease enzymes. ${ }^{60}$ In these cases, hydrolysis of a phosphate ester by a nucleophilic water involves binding to two $\mathrm{Mg}$ 's with nonequal 5-, 6-fold coordination, and a vicinal mechanism where the substrate moves into a bridging position with a trigonal geometry, to form a four-center TS with the nucleophile hydroxyl group attacking from its $\mathrm{Mg}$-coordinating position. ${ }^{61-65}$ The structural analogy between the two reactions suggests that the evolutionary pressure has selected among the many chemically possible pathways the most advantageous organization of the $\mathrm{Mg}$ ions and their coordinating groups to catalyze a nucleophilic attack having both the substrate and the nucleophile as initial coordinating ligands to the metal centers. The Grignard reaction puzzle is finally assembling together with potential impacts on related chemistry.

\section{ASSOCIATED CONTENT}

\section{SI Supporting Information}

The Supporting Information is available free of charge at https://pubs.acs.org/doi/10.1021/jacs.9b11829.

Reference coupled-cluster calculations and benchmark BDE calculations, and structures of $\mathrm{Mg}\left(\mathrm{CH}_{3}\right)_{2}, \mathrm{Mg}$ $\left(\mathrm{CH}_{3}\right)_{2}\left(\mathrm{CH}_{3} \mathrm{CHO}\right)$, and $\mathrm{CH}_{3} \mathrm{Mg}\left(\mathrm{OCH}\left(\mathrm{CH}_{3}\right)_{2}\right)$ in THF (PDF)

\section{AUTHOR INFORMATION}

\section{Corresponding Authors}

Odile Eisenstein - Department of Chemistry and Hylleraas Centre for Quantum Molecular Sciences, University of Oslo, Oslo 0315, Norway; ICGM, Universite de Montpellier, CNRS, ENSCM, , Montpellier 34095 Cedex 5, France; 이이.org/ 0000-0001-5056-0311; Email: odile.eisenstein@ umontpellier.fr

Michele Cascella - Department of Chemistry and Hylleraas Centre for Quantum Molecular Sciences, University of Oslo, Oslo 0315, Norway; 이이.org/0000-0003-2266-5399; Email: michele.cascella@kjemi.uio.no

\section{Authors Oslo, Oslo 0315, Norway Universität Mainz, Mainz 55128, Germany \\ Complete contact information is available at: https://pubs.acs.org/10.1021/jacs.9b11829}

Raphael Mathias Peltzer - Department of Chemistry and Hylleraas Centre for Quantum Molecular Sciences, University of

Jürgen Gauss - Department Chemie, Johannes Gutenberg-

\section{Notes}

The authors declare no competing financial interest.

\section{ACKNOWLEDGMENTS}

This work was supported by the Research Council of Norway (RCN) through the CoE Hylleraas Center for Quantum Molecular Sciences (Grant number 262695) and by the Norwegian Supercomputing Program (NOTUR) (Grant number NN4654K). M.C. and J.G. acknowledge funding by the Deutsche Forschungsgemeinschaft (DFG) within the project B5 of the TRR 146 (project number 233630050). We thank Mats Tilset for being at the right place at the right time to ask the right question. We also thank Filippo Lipparini for useful discussions.

\section{REFERENCES}

(1) Vollhardt, K.; Schore, N. Organic Chemistry: Structure and Function; W. H. Freeman: New York, 2014.

(2) Grignard, V. C. Sur quelques nouvelles combinaisons organométalliques du magnésium et leur application à des synthèses daalcools et d'hydrocarbures. Compt. Rend. Hebd. Séances Acad. Sci. 1900, 130, 1322-24.

(3) Rappoport, Z., Marek, I., Eds. The Chemistry of Organomagnesium Compounds; Wiley-VCH: Weinheim, Germany, 2008.

(4) Schlenk, W.; Schlenk, W. Über die Konstitution der Grignardschen Magnesiumverbindungen. Ber. Dtsch. Chem. Ges. B 1929, 62, 920-924.

(5) Seyferth, D. The Grignard Reagents. Organometallics 2009, 28, $1598-1605$.

(6) Silverman, G. S.; Rakita, P. E. Handbook of Grignard Reagents; CRC Press: New York, 1996.

(7) Robertson, S. D.; Uzelac, M.; Mulvey, R. E. Alkali-metalmediated synergistic effects in polar main group organometallic chemistry. Chem. Rev. 2019, 119, 8332-8405.

(8) Fauvarque, J.; Rouget, E. Compt. Rend. Hebd. Séances Acad. Sci., Ser. C 1968, 257, 1355.

(9) Blomberg, C.; Mosher, H. A radical process in a reaction of a Grignard compound. J. Organomet. Chem. 1968, 13, 519-522.

(10) Blomberg, C.; Grootveld, H.; Gerner, T.; Bickelhaupt, F. Radical formation during reactions of Grignard reagents with quinones. J. Organomet. Chem. 1970, 24, 549-553.

(11) Ashby, E. C.; Nackashi, J.; Parris, G. E. Composition of Grignard compounds. X. NMR, IR, and molecular association studies of some methylmagnesium alkoxides in diethyl ether, tetrahydrofuran, and benzene. J. Am. Chem. Soc. 1975, 97, 3162-3171.

(12) Ashby, E. C.; Lopp, I. G.; Buhler, J. D. Mechanisms of Grignard reactions with ketones. Polar vs. single electron transfer pathways. J. Am. Chem. Soc. 1975, 97, 1964-1966.

(13) Ashby, E. C. A detailed description of the mechanism of reaction of Grignard reagents with ketones. Pure Appl. Chem. 1980, $52,545-569$.

(14) Ashby, E. C.; Bowers, J. R. Organometallic reaction mechanisms. 17. Nature of alkyl transfer in reactions of Grignard reagents with ketones. Evidence for radical intermediates in the formation of 1,2-addition product involving tertiary and primary Grignard reagents. J. Am. Chem. Soc. 1981, 103, 2242-2250.

(15) Lund, T.; Pedersen, M. L.; Frandsen, L. A. Does the reaction between fluorenone and grignard reagents involve free fluorenone anion radicals? Tetrahedron Lett. 1994, 35, 9225-9226.

(16) Blomberg, C.; Salinger, R. M.; Mosher, H. S. Reaction of Grignard reagent from neopentyl chloride with benzophenone. A nuclear magnetic resonance study. J. Org. Chem. 1969, 34, 23852388.

(17) Hoffmann, R. W.; Hölzer, B. Concerted and stepwise Grignard additions, probed with a chiral Grignard reagent. Chem. Commun. 2001, 491-492.

(18) Hoffmann, R. W. The quest for chiral Grignard reagents. Chem. Soc. Rev. 2003, 32, 225-230.

(19) Gajewski, J. J.; Bocian, W.; Harris, N. J.; Olson, L. P.; Gajewski, J. P. Secondary deuterium kinetic isotope effects in irreversible 
additions of hydride and carbon nucleophiles to aldehydes: a spectrum of transition states from complete bond formation to single electron transfer. J. Am. Chem. Soc. 1999, 121, 326-334.

(20) Otte, D. A. L.; Woerpel, K. A. Evidence that Additions of Grignard Reagents to Aliphatic Aldehydes do Not Involve SingleElectron-Transfer Processes. Org. Lett. 2015, 17, 3906-3909.

(21) Garst, J. F.; Soriaga, M. P. Grignard reagent formation. Coord. Chem. Rev. 2004, 248, 623-652.

(22) Chen, Z.-N.; Fu, G.; Xu, X. Theoretical studies on Grignard reagent formation: radical mechanism versus non-radical mechanism. Org. Biomol. Chem. 2012, 10, 9491-9500.

(23) Shao, Y.; Liu, Z.; Huang, P.; Liu, B. A unified model of Grignard reagent formation. Phys. Chem. Chem. Phys. 2018, 20, 11100-11108.

(24) Axten, J.; Troy, J.; Jiang, P.; Trachtman, M.; Bock, C. W. An ab initio molecular orbital study of the Grignard reagents $\mathrm{CH}_{3} \mathrm{MgCl}$ and $\left[\mathrm{CH}_{3} \mathrm{MgCl}\right]_{2}$ : the Schlenk equilibrium. Struct. Chem. 1994, 5, 99108.

(25) Ehlers, A. W.; van Klink, G. P. M.; van Eis, M. J.; Bickelhaupt, F.; Nederkoorn, P. H. J.; Lammertsma, K. Density-Functional study of (solvated) Grignard complexes. J. Mol. Model. 2000, 6, 186-194.

(26) Tammiku, J.; Burk, P.; Tuulmets, A. 1,10-phenanthroline and its complexes with magnesium compounds. Disproportionation equilibria. J. Phys. Chem. A 2001, 105, 8554-8561.

(27) Tammiku-Taul, J.; Burk, P.; Tuulmets, A. Theoretical study of magnesium compounds: The Schlenk equilibrium in the gas phase and in the presence of $\mathrm{Et}_{2} \mathrm{O}$ and THF molecules. J. Phys. Chem. A 2004, 108, 133-139.

(28) Yamabe, S.; Yamazaki, S. In The Chemistry of Organomagnesium Compounds; Rappoport, Z., Marek, I., Eds.; Wiley-VCH: Weinheim, Germany, 2008; pp 369-402.

(29) Yamazaki, S.; Yamabe, S. A computational study on addition of grignard reagents to carbonyl compounds. J. Org. Chem. 2002, 67, 9346-9353.

(30) Mori, T.; Kato, S. Grignard reagents in solution: Theoretical study of the equilibria and the reaction with a carbonyl compound in diethyl ether solvent. J. Phys. Chem. A 2009, 113, 6158-6165.

(31) Peltzer, R. M.; Eisenstein, O.; Nova, A.; Cascella, M. How solvent dynamics controls the Schlenk equilibrium of Grignard reagents: A computational study of $\mathrm{CH}_{3} \mathrm{MgCl}$ in tetrahydrofuran. J. Phys. Chem. B 2017, 121, 4226-4237.

(32) Hohenberg, P.; Kohn, W. Inhomogeneous electron gas. Phys. Rev. 1964, 136, B864-B871.

(33) Kohn, W.; Sham, L. J. Self-consistent equations including exchange and correlation effects. Phys. Rev. 1965, 140, 1133.

(34) Perdew, J. P.; Burke, K.; Ernzerhof, M. Generalized gradient approximation made simple. Phys. Rev. Lett. 1996, 77, 3865-3868.

(35) VandeVondele, J.; Hutter, J. Gaussian basis sets for accurate calculations on molecular systems in gas and condensed phases. $J$. Chem. Phys. 2007, 127, 114105.

(36) Goedecker, S.; Teter, M.; Hutter, J. Separable dual-space Gaussian pseudopotentials. Phys. Rev. B 1996, 54, 1703-1710.

(37) Grimme, S.; Antony, J.; Ehrlich, S.; Krieg, H. A consistent and accurate $a b$ initio parametrization of density functional dispersion correction (DFT-D) for the 94 elements H-Pu. J. Chem. Phys. 2010, 132, 154104.

(38) Swope, W. C.; Andersen, H. C.; Berens, P. H.; Wilson, K. R. A computer simulation method for the calculation of equilibrium constants for the formation of physical clusters of molecules: Application to small water clusters. J. Chem. Phys. 1982, 76, 648.

(39) Bussi, G.; Donadio, D.; Parrinello, M. Canonical sampling through velocity rescaling. J. Chem. Phys. 2007, 126, 014101.

(40) Nosé, S. A unified formulation of the constant temperature molecular dynamics methods. J. Chem. Phys. 1984, 81, 511-519.

(41) Hoover, W. G. Canonical dynamics: Equilibrium phase-space distributions. Phys. Rev. A 1985, 31, 1695-1697.

(42) Martyna, G. J.; Klein, M. L.; Tuckerman, M. Nosé-Hoover chains: The canonical ensemble via continuous dynamics. J. Chem. Phys. 1992, 97, 2635-2643.
(43) Humphrey, W.; Dalke, A.; Schulten, K. VMD: Visual molecular dynamics. J. Mol. Graphics 1996, 14, 33-38.

(44) Carter, E. A.; Ciccotti, G.; Heynes, J. T.; Kapral, R. Constrained reaction coordinate dynamics for the simulation of rare events. Chem. Phys. Lett. 1989, 156, 472-477.

(45) Marenich, A. V.; Cramer, C. J.; Truhlar, D. G. Universal solvation model based on solute electron density and on a continuum model of the solvent defined by the bulk dielectric constant and atomic surface tensions. J. Phys. Chem. B 2009, 113, 6378-6396.

(46) Zhao, Y.; Truhlar, D. G. The M06 suite of density functionals for main group thermochemistry, thermochemical kinetics, noncovalent interactions, excited states, and transition elements: two new functionals and systematic testing of four M06-class functionals and 12 other functionals. Theor. Chem. Acc. 2008, 120, 215-241.

(47) Ditchfield, R.; Hehre, W. J.; Pople, J. A. Self-consistent molecular-orbital methods. IX. An extended Gaussian-type basis for molecular-orbital studies of organic molecules. J. Chem. Phys. 1971, 54, 724-728.

(48) Frisch, M. J.; Trucks, G. W.; Schlegel, H. B.; Scuseria, G. E.; Robb, M. A.; Cheeseman, J. R.; Scalmani, G.; Barone, V.; Petersson, G. A.; Nakatsuji, H.; Li, X.; Caricato, M.; Marenich, A. V.; Bloino, J.; Janesko, B. G.; Gomperts, R.; Mennucci, B.; Hratchian, H. P.; Ortiz, J. V.; Izmaylov, A. F.; Sonnenberg, J. L.; Williams-Young, D.; Ding, F.; Lipparini, F.; Egidi, F.; Goings, J.; Peng, B.; Petrone, A.; Henderson, T.; Ranasinghe, D.; Zakrzewski, V. G.; Gao, J.; Rega, N.; Zheng, G.; Liang, W.; Hada, M.; Ehara, M.; Toyota, K.; Fukuda, R.; Hasegawa, J.; Ishida, M.; Nakajima, T.; Honda, Y.; Kitao, O.; Nakai, H.; Vreven, T.; Throssell, K.; Montgomery, J. A., Jr.; Peralta, J. E.; Ogliaro, F.; Bearpark, M. J.; Heyd, J. J.; Brothers, E. N.; Kudin, K. N.; Staroverov, V. N.; Keith, T. A.; Kobayashi, R.; Normand, J.; Raghavachari, K.; Rendell, A. P.; Burant, J. C.; Iyengar, S. S.; Tomasi, J.; Cossi, M.; Millam, J. M.; Klene, M.; Adamo, C.; Cammi, R.; Ochterski, J. W.; Martin, R. L.; Morokuma, K.; Farkas, O.; Foresman, J. B.; Fox, D. J. Gaussian 09, revision B.01; Gaussian, Inc.: Wallingford, CT, 2016.

(49) Raghavachari, K.; Trucks, G. W.; Pople, J. A.; Head-Gordon, M. A fifth-order perturbation comparison of electron correlation theories. Chem. Phys. Lett. 1969, 157, 479-483.

(50) Dunning, T. H. Gaussian basis sets for use in correlated molecular calculations. I. The atoms boron through neon and hydrogen. J. Chem. Phys. 1989, 90, 1007-1023.

(51) CFOUR, a quantum-chemical program package written by Stanton, J. F.; Gauss, J.; Cheng, L.; Harding, M. E.; Matthews, D. A.; Szalay, P. G. with contributions from Auer, A. A.; Bartlett, R. J.; Benedikt, U.; Berger, C.; Bernholdt, D. E.; Bomble, Y. J.; Christiansen, O.; Engel, F.; Faber, R.; Heckert, M.; Heun, O.; Hilgenberg, M.; Huber, C.; Jagau, T.-C.; Jonsson, D.; Jusélius, J.; Kirsch, T.; Klein, K.; Lauderdale, W. J.; Lipparini, F.; Metzroth, T.; Mück, L.A.; O’Neill, D. P.; Price, D. R.; Prochnow, E.; Puzzarini, C.; Ruud, K.; Schiffmann, F.; Schwalbach, W.; Simmons, C.; Stopkowicz, S.; Tajti, A.; Vázquez, J.; Wang, F.; Watts, J. D. and the integral packages MOLECULE (Almlöf, J.; Taylor, P. R.), PROPS (Taylor, P. R.), ABACUS (Helgaker, T.; Jensen, H. J. Aa.; Jørgensen, P.; Olsen, J.), and ECP routines by Mitin, A. V. and van Wüllen, C.; website: http://www.cfour.de.

(52) Buergi, H. B.; Dunitz, J. D.; Shefter, E. Geometrical reaction coordinates. II. Nucleophilic addition to a carbonyl group. J. Am. Chem. Soc. 1973, 95, 5065-5067.

(53) Buergi, H. B.; Lehn, J. M.; Wipff, G. Ab initio study of nucleophilic addition to a carbonyl group. J. Am. Chem. Soc. 1974, 96, 1956-1957.

(54) Walker, F. W.; Ashby, E. C. Composition of Grignard compounds. VI. Nature of association in tetrahydrofuran and diethyl ether solutions. J. Am. Chem. Soc. 1969, 91, 3845-3850.

(55) Holm, T. Thermochemical bond dissociation energies of carbon-magnesium bonds. J. Chem. Soc., Perkin Trans. 2 1981, 2, 464-467.

(56) We consider here thermodynamically equilibrated solutions of the Grignard reagent. In fact, the formation of the Grignard reagent may occur via a radical mechanism; see, for instance, the recent study: Henriques, A. M.; Barbosa, A. G. H. Chemical bonding and the 
equilibrium composition of Grignard reagents in ethereal solution. J. Phys. Chem. A 2011, 115, 12259-12270.

(57) Ziegler, D. S.; Wei, B.; Knochel, P. Improving the halogenmagnesium exchange by using new turbo-Grignard reagents. Chem. Eur. J. 2019, 25, 2695-2703.

(58) Harutyunyan, S. R.; Lopez, F.; Browne, W. R.; Correa, A.; Pena, D.; Badorrey, R.; Meetsma, A.; Minaard, A. J.; Feringa, B. L. On the mechanism of the copper-catalyzed enantioselective 1,4-addition of Grignard reagents to $\alpha, \beta$-unsaturated carbonyl compounds. J. Am. Chem. Soc. 2006, 128, 9103-9118.

(59) Lopez, F.; Minaard, A. J.; Feringa, B. L. Catalytic enantioselective conjugate addition with Grignard reagents. Acc. Chem. Res. 2007, 40, 179-188.

(60) Seitz, T. A.; Seitz, J. A. A general two-metal-ion mechanism for catalytic RNA. Proc. Natl. Acad. Sci. U. S. A. 1993, 90, 6498-6502.

(61) De Vivo, M.; Dal Peraro, M.; Klein, M. L. Phosphodiester cleavage in ribonuclease $\mathrm{H}$ occurs via an associative two-metal-aided catalytic mechanism. J. Am. Chem. Soc. 2008, 130, 10955-10962.

(62) Rosta, E.; Nowotny, M.; Yang, W.; Hummer, G. Catalytic mechanism of RNA backbone cleavage by ribonuclease $\mathrm{H}$ from quantum mechanics/molecular mechanics simulations. J. Am. Chem. Soc. 2011, 133, 8934-8941.

(63) Casalino, L.; Palermo, G.; Rothlisberger, U.; Magistrato, A. Who activates the nucleophile in ribozyme catalysis? An answer from the splicing mechanism of group II introns. J. Am. Chem. Soc. 2016, $138,10374-10377$.

(64) Genna, V.; Vidossich, P.; Ippoliti, E.; Carloni, P.; De Vivo, M. A self-activated mechanism for nucleic acid polymerization catalyzed by DNA/RNA polymerases. J. Am. Chem. Soc. 2016, 138, 14592-14598.

(65) Genna, V.; Donati, E.; De Vivo, M. The catalytic mechanism of DNA and RNA polymerases. ACS Catal. 2018, 8, 11103-11118. 